\title{
Das Tuch
}

\section{Erhard Taverna}

- Museo della Sindone,

Via Domenico 28, Turin.

- Chiesa del Santo Volto, Turin,

Bauzeit 2004-2006

erhard.taverna[at]saez.ch

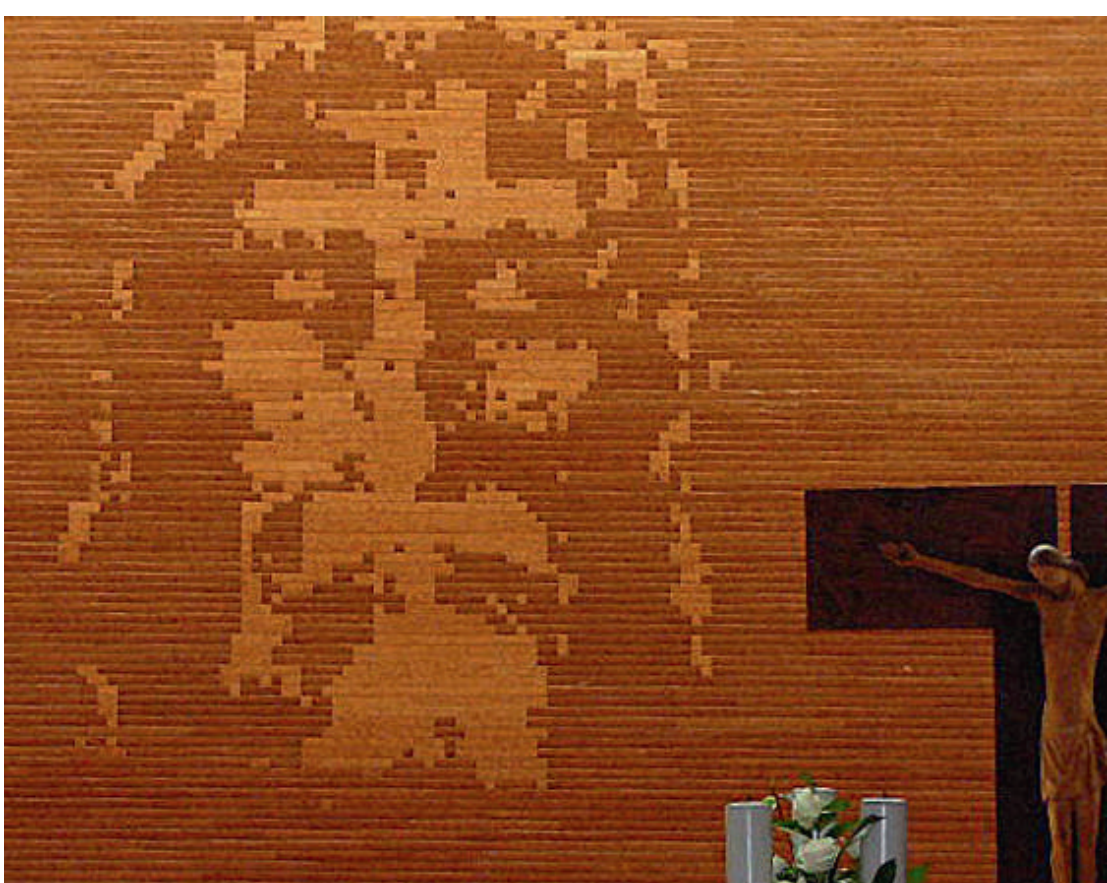

Pixelrelief aus Marmor mit dem Antlitz des Turiner Grabtuchs in der Chiesa del Santo Volto, Turin.
Ein kurzer Film erklärt den Besuchern die geheimnisvolle Landkarte eines Leinentuchs, gut vier Meter lang und etwas über einen Meter breit. Brandspuren, Wasserflecken und vereinzelte Flickstellen sind auch dem ungeübten Auge sichtbar. Entlang der Mittellinie sind schattenhafte Umrisse von zwei Kopf an Kopf liegenden Figuren zu erkennen. Die gleiche Person, einmal von hinten, einmal von vorne. Bei den Nahaufnahmen sprechen medizinische Forensiker von venösen und arteriellen Blutflecken, typischen

\section{«Die gesicherte Überlieferung beginnt erst im 13. Jahrhundert.»}

Verletzungsstellen, Schwellungen und Stichwunden, zugefügt von einer tausendfach abgebildeten Ikonographie aus Dornen, Nägeln, einer Lanze und Peitschenhieben. Das Nasenbein ist gebrochen, Schultern und Kniescheiben sind aufgeschürft. Ein Fotonegativ von 1898 zeigt frontal ein Antlitz mit kurzem Bart und langen Seitenhaaren. Mit dieser

ersten Ablichtung beginnt eine Forschungsgeschichte, die wohl nie enden wird. Dem Glauben genügen die Evangelien, die Wissenschaft muss nach Beweisen suchen.

Was mit einem Gerichtsprozess vor dem Stadthalter Pontius Pilatus begann, setzt sich als endlose Indiziensuche fort. Die gesicherte Überlieferung beginnt erst im 13. Jahrhundert mit dem Bericht eines Kreuzfahrers, der das Grabtuch Christi in Konstantinopel gesehen haben will. Aus dem Nahen Osten gelangt das Tuch schliesslich nach Frankreich, wo es die Herren von Savoyen von Chambéry nach Turin bringen. 1694 wird das Leinen in die von Guarino Guarini entworfene Kapelle überführt. Die wichtigste Relique der Christenheit bleibt die längste Zeit in einem lichtgeschützten, mit Argon gefüllten Stahl-Glas-Sarg eingesperrt. Nur alle zehn bis zwanzig Jahre erlaubt ein Papst die öffentliche Zurschaustellung, was jeweils Millionen Pilger in die piemontesische Hauptstadt lockt.

Die Forschungsgeschichte entspricht dem jeweiligen Stand der Technik. Den belichteten Glasplatten folgen 1973 die Pollenanalysen des Botanikers und Kriminologen Max Frei von der Zürcher Stadtpolizei. Israelische Forscher bestätigen, dass einzelne Pollen nur im Gebiet von Palästina vorkommen. 1988 führen Labors in Tucson, Oxford und Zürich nach der Radiokarbonmethode eine Altersbestimmung durch. Die entnommenen Proben stammen aus einem Zeitraum von 1260 bis 1390. Zahlreiche, zum Teil stichhaltige Gegenargumente lassen heute berechtigte Zweifel an diesen Resultaten aufkommen. Eine mittelalterliche Fälschung ist mit Sicherheit ausgeschlossen. Das Gewebe wurde mehrmals geflickt, vielleicht stammen die Materialproben aus nachträglich ausgebesserten Stellen. Chemische Untersuchungen weisen Blut und Amine nach, Farbpigmente sind nicht nachweisbar. Die Wissenschaft vom Grabtuch, die Sindonologie, beschäftigt Spezialisten aller Fachrichtungen, vom Kunsthistoriker zum Mathematiker und Textilspezialisten, vom Chemiker zum Kernphysiker und Computerfachmann. Bibliotheken, Dokufilme und Computerportale bedienen weltweit Anhänger und Gegner. An jedem weiteren Kongress, zuletzt 2010 in Lima, stellen Forscher neue Ergebnisse vor. Spuren hellenistischer Münzabdrücke auf den Augenlidern, neuste 3-D-Bilder aufgrund von digitalisierten Farbvariationen, aramäische Schriftzeichen und komplizierte Wahrscheinlichkeitsrechnungen, die alle die Authentizität des Fundes belegen sollen. Jedes Resultat führt zu Gegenexpertisen, Verschwörungstheorien und Be- 
trugsvorwürfen. Nur der Schmerzensmann schweigt. Am Anfang war das Bilderverbot. Dann kam der triumphierende Christus, der gute Hirte, den wohlhabende Römer in antiker Tradition als Schafträger abbildeten. Das Kreuz wird erst in den Katastrophenjahren der Völkerwanderungen zum Symbol, und das Kruzifix, als dominierender Mittelpunkt der Kirche, kommt Jahrhunderte später.

Von weit älteren Befunden, wie ägyptischen $\mathrm{Mu}$ mien, dem Archimedes-Palimpsest oder vom Eismann aus dem Ötztal, gibt es gesicherte Daten. Sie provozieren keine Glaubenskämpfe, weil die Erwartungen andere sind. Einen Gottesbeweis kann auch die Forschung nicht vollbringen. Ist es überhaupt wichtig, ob es sich um den Nazarener von Golgatha handelt? Andreas Eschbach schildert in seinem Thriller «Das Jesusvideo» die Jagd nach den Videoaufnahmen eines Zeitreisenden. Das Gedankenexperiment relativiert die Bedeutung der archäometrischen Suche nach dem Gekreuzigten. Dass es ihn gab, bezeugen andere Quellen. Warum seine Faszination auch nach 2000 Jahren noch anhält, bleibt ein Mysterium, das kein Tuch erklärt.

2006 wurde in Turin die Kirche «Santo Volto» von Mario Botta eingeweiht. Das Pixelrelief aus Marmor im kreisrunden Gebetsraum zeigt das Antlitz des Turiner Grabtuchs. Der wunderschöne Sakralbau auf dem ehemaligen Fabrikgelände ist still und leer. Wenn das Gesicht spricht, dann hier. 